\title{
ANALISIS PENGENDALIAN KUALITAS PROSES HOT PRESS PADA PRODUK CACAT OUTSOLE MENGGUNAKAN METODE STATISTICAL PROCESSING CONTROL (SPC) DAN FAILURE MODE EFFECT AND ANALYSIS (FMEA) DI PT. KMK GLOBAL SPORTS 2
}

\author{
Sofian Bastuti'), Dadang Kurnia ${ }^{1)}$, Adi Sumantri ${ }^{2)}$ \\ ${ }^{1}$ Dosen Fakultas Teknik Program Studi Teknik Industri, Universitas Pamulang \\ ${ }^{2}$ Mahasiswa Program Studi Teknik Industri, Universitas Pamulang \\ sofianbastuti@yahoo.co.id
}

\begin{abstract}
ABSTRAK
PT KMK Global Sports 2, sebagai perusahaan yang menghasilkan produk sepatu bermerek converse yang memprioritaskan kualitas nomor satu. Oleh karena itu PT. KMK Global Sports 2 dituntut untuk menghasilkan sepatu sesuai dengan standar mutu yang telah ditetapkan oleh pihak Converse sebagai upaya untuk memenuhi tuntutan konsumen sepatu Converse. Tanpa menjaga mutu produk sepatunya, PT. KMK Global Sports 2 akan dihadapkan pada risiko yaitu terputusnya kontrak kerja sama yang selama ini telah terjalin dengan baik. Oleh sebab itu kualitas merupakan salah satu faktor penting yang harus dijaga. Pada penelitian ini penulis menganalisa cacat pada bagian sepatu yaitu outsole AS 475 warna brown dengan metode statistical processing control (SPC) dan metode failure mode and effect analysis (FMEA) untuk meminimalkan produk cacat. Penelitian ini dilakukan dengan mengambil data laporan produksi dan cacat pada tahun 2015. Hasil dari pengolahan data menunjukan bahwa setelah adanya usulan perbaikan dengan hasil sebelumnya rata-rata persentase cacat pada tahun 2015 sebesar 1,57\% dan setelah perbaikan rata-rata persentase delapan bulan selanjutnya mengalami penurunan dengan hasil sebesar 0,80\%.
\end{abstract}

Kata kunci : AS 475 Brown Outsole, Cacat, SPC dan FMEA

\section{PENDAhUluan}

PT. KMK Global Sports 2 adalah sebuah perusahaan yang bergerak dibidang manufaktur produksi sepatu bermerek Converse. Didalam memproduksi sepatu PT. KMK Global Sports 2 bisa memproduksi lebih dari 1 juta sepatu pertahunnya, adapun dari produksi setiap tahunnya dalam bulan ke bulan banyak sekali terjadinya produk cacat yang diakibatkan oleh berbagai faktor seperti human error, raw material, mesin error dan lain-lain. Dari data yang dimiliki oleh PT. KMK Global Sports 2 dalam hal ini penulis menggunakan data produksi outsole jenis AS 475 warna brown adalah komponen yang ada dalam produk sepatu bahwa pada tahun 2015 telah terjadi cacat produk sebanyak 23.213 pcs atau $1,57 \%$ dari jumlah produksi yang dibuat dalam setahun. Dalam penelitian ini metode SPC (Statistical Processing Control) dan metode FMEA (Failure Mode and Effect Analysis) yang dilakukan dalam upaya meminimalkan produk cacat tersebut.

Dengan kondisi tersebut, PT. KMK Global Sports 2 memiliki jumlah produksi yang cukup besar. Cacat yang terjadi sungguh sangat merugikan, jika kita kalkulasikan produk cacat tersebut maka dapat kita hitung seperti berikut, pada tahun 2015 telah terjadi cacat sebanyak 23.213 pcs outsole dan apabila harga rata-rata dari produk tersebut adalah $\$$ 5,- atau Rp 65.000,- per pcs (kurs Rp 13.000,/dollar) maka jumlah kerugian yang diakibatkan dari cacat tersebut adalah 23.213 X Rp 65.000,- = Rp 1.508.845.000, dengan demikian tanpa disadari PT. KMK Global Sports 2 ini pada tahun 2015 telah mengalami kerugian uang sejumlah $\mathrm{Rp}$ 1.508.845.000,belum lagi kerugian yang lainnya seperti waktu terbuang, tenaga yang terbuang, energy yang terbuang dan segenap pemikiran yang terbuang sia-sia. Apabila jumlah kerugian ini kita alokasikan untuk pembayaran upah 
karyawan selama satu tahun maka maka Rp 1.508.845.000/12 bulan $=\operatorname{Rp} 125.737 .000,-$ jika UMR saat ini Rp 3.120.000,- maka Rp $125.737 .000 / \operatorname{Rp} 3.120 .000=40,3$. Jadi dengan kata lain kerugian tersebut mestinya bisa dialokasikan untuk pembayaran upah karyawan sebanyak 40 orang. Dari itu semua penulis berusaha memberikan suatu alternatif atau usulan perbaikan masalah dari produk cacat yang sering terjadi dengan lebih fokus pada upaya perbaikan untuk meminimalkan produk cacat.

\section{DASAR TEORI}

\section{A. Pengertian Kualitas}

Dewasa ini semakin disadari akan pentingnya kualitas yang baik untuk menjaga keseimbangan kegiatan produksi dan pemasaran suatu produk. Hal ini timbul dari sikap konsumen yang menginginkan barang dengan kualitas yang terjamin dan semakin ketatnya persaingan antara perusahaan yang sejenis. Oleh karena itu pihak perusahaan perlu mengambil kebijaksanaan untuk menjaga kualitas produknya agar diterima konsumen dan dapat bersaing dengan produk sejenis dari perusahaan lain serta dalam rangka menunjang program jangka panjang perusahaan yaitu mempertahankan pasar yang telah ada atau menambah pasar perusahaan. Adapun hal tersebut dapat dilakukan melalui pengendalian kualitas. Pengertian kualitas menurut beberapa ahli antara lain:

1. Kualitas merupakan suatu kondisi yang berhubungan dengan produk dan jasa manusia, proses dan lingkungan yang memenuhi atau melebihi harapan (Tjiptono, 2001:4)

2. Kualitas merupakan totalitas bentuk dan karakteristik barang/jasa yang menunjukan kemampuannya untuk memutuskan kebutuhan yang tampak jelas maupun yang tersembunyi (Render, 2001:92)

3. Kualitas merupakan jumlah dari atribut atau sifat-sifat sebagaimana dideskripsikan didalam produk yang bersangkutan (Ahyari, 1990:238)

4. Kualitas adalah keseluruhan ciri dan karakteristik produk atau jasa yang kemampuannya dapat memuaskan kebutuhan konsumen (SNI 19-8402-1991)
5. Kualitas adalah kesesuaian dengan tujuan atau manfaatnya (Joseph M. Juran, 1962).

Jadi dapat disimpulkan kualitas adalah totalitas bentuk, karakteristik dan atribut sebagaimana dideskripsikan didalam produk (barang/jasa), proses dan lingkungan yang memenuhi atau melebihi harapan/kebutuhan konsumen.

\section{B. Produk Cacat}

Produk cacat merupakan produk yang dihasilkan tidak sesuai dengan standar kualitas yang sudah ditentukan. Standar kualitas yang baik menurut konsumen adalah produk tersebut dapat digunakan sesuai dengan kebutuhan dan keinginan mereka. Apabila konsumen sudah merasa bahwa produk tersebut tidak dapat digunakan sesuai kebutuhan dan keinginan mereka maka produk tersebut akan dikatakan sebagai produk cacat.

Untuk mengatasi produk cacat yang dihasilkan, produsen hanya dapat melakukan pencegahan terhadap terjadinya cacat produk. Untuk melakukan perbaikan sangat sulit dikarenakan memperbaiki produk yang cacat tetapi tidak pada proses produksinya sama saja akan menambah biaya. Produsen sebaiknya melakukan pencegahan terjadinya produk cacat dengan cara menyelidiki apakah terjadi kesalahan dalam proses produksinya sehingga dapat didapatkan penyebab produk cacat itu terjadi.

\section{Stastical Processing Control (SPC)}

Statistical Processing Control (SPC) merupakan sebuah teknik statistik yang digunakan secara luas untuk memastikan bahwa proses memenuhi standar. Dengan kata lain, selain SPC merupakan sebuah proses yang digunakan untuk mengawasi, standar, membuat pengukuran dan mengambil tindakan perbaikan selagi sebuah produk atau jasa sedang diproduksi. (Render dan Heizer, 2005, p286).

Menurut Gerald Smith (2003:p1) Statistical Process Control merupakan kumpulan dari metode-metode produksi dan konsep manajemen yang dapat digunakan untuk mendapatkan efisiensi, produktifitas dan kualitas untuk memproduksi produk yang kompetitif dengan tingkat yang maksimum, dimana Statistical Process Control melibatkan penggunaan signal-signal statistic untuk meningkatkan performa dan untuk memelihara 
pengendalian dari produksi pada tingkat kualitas yang lebih tinggi.

Pengertian lain dari Statistical Process Control menurut pendapat Vincent Gasperz (1998:p1) ialah suatu terminology yang mulai digunakan sejak tahun 1970-an untuk menjabarkan penggunaan teknik-teknik statistical dalam memantau dan meningkatkan performansi proses menghasilkan produk yang berkualitas.

\section{METODOLOGI PENELITIAN}

\section{A. Lokasi Penelitian}

Untuk memfokuskan kegiatan penelitian yang dilakukan, maka ruang lingkup penelitian dibatasi berdasarkan tempat dan objek penelitian sebagai berikut:

1. Tempat dan Waktu Penelitian

a. Tempat Penelitian

Data ini bersumber dari PT. KMK Global Sports 2 yang berlokasi jln. $\begin{array}{llll}\text { Raya } & \text { Serang } & \mathrm{km} .8 & \text { Telesonic }\end{array}$ Tangerang. Yang bergerak dibidang manufaktur yang memproduksi sepatu.

b. Waktu Penelitian

Penelitian dilakukan dari bulan Mei 2016 sampai Juli 2016

2. Objek Penelitian

Pelaksanaan penelitian ini dilakukan pada bagian hot press outsole department technical, proses pembuatan outsole sepatu ini dimulai dari pengambilan sampel produk cacat yang sering terjadi untuk melalui tahapan-tahapan pengujian yang akan dilakukan.

\section{B. Jenis Penelitian}

Penelitian harus mempunyai tujuan dan arah yang jelas. Dengan adanya tujuan yang jelas dan terencana dengan baik maka kegiatan penelitian akan menjadi jelas. Karena itu diperlukan sistematika kegiatan yang akan dilaksanakan dengan metode dan prosedur yang tepat mengarah kepada sasaran atau target yang telah ditetapkan.

Penelitian yang dilakukan berdasarkan sifatnya termasuk penelitian deskriptif. Metode ini meneliti kondisi pada masa sekarang untuk membuat gambaran, deskripsi secara matematis dan jelas mengenai proses produksi yang berlangsung yang dapat digunakan untuk membuat rancangan perbaikan.
Untuk mencapai tujuan dari penelitian ini, maka penulis menggunakan metode Statistical Processing Control (SPC) dan Failure Mode and Effect Analysis (FMEA) digunakan untuk upaya perbaikan meminimalkan produk cacat. Dari tingkat kecacatan produk yang tinggi bisa diminimalkan dengan menggunakan metode Statistical Processing Control (SPC) dan Failure Mode and Effect Analysis yang melalui tahapan-tahapan metodenya.

\section{Data dan Sumber Data}

Dalam upaya untuk memperoleh datadata pada penelitian ini, maka penulis melakukan berbagai upaya untuk pengumpulan datanya. Dalam hal ini data tersebut secara garis besar terbagi dalam dua kategori yaitu:

1. Data Primer

Data primer adalah data yang diperoleh langsung dari sumbernya, diamati dan dicatat untuk pertama kalinya. Data primer secara khusus dikumpulkan oleh peneliti untuk kepentingan penelitian. Data primer diperoleh dari bagian Hot Press Outsole Departement Technical PT. KMK Global Sports 2.

2. Data Sekunder

Data sekunder diperoleh dari hasil penelitian kepustakaan dengan membaca dan mempelajari buku-buku, artikel-artikel dan literatur-literatur agar mendapatkan pengertian tentang teori-teori serta metode analisis yang berhubungan dengan objek yang diteliti.

\section{Teknik Pengumpulan Data}

Data yang digunakan dalam penelitian adalah data primer dan sekunder. Data primer diambil dari pengamatan dan wawancara dengan pihak terkait dengan kata lain menggunakan metode purposive. Sedangkan data sekunder diperoleh dari dokumen perusahaan dan beberapa pustaka terkait. Agar diperoleh data yang dapat di uji kebenarannya maka dalam penelitian ini menggunakan Teknik pengumpulan data sebagai berikut:

1. Landasan Teori

Yaitu bentuk penelitian yang dilakukan dengan membaca literatur-literatur, karangan ilmiah serta berbagai sumber pustaka terkait lainya guna memperoleh landasan teori yang memadai untuk melakukan pembahasan. 
2. Penelitian Lapangan

Penelitian yang dilakukan secara langsung pada lokasi penelitian dengan menggunakan teknik pengamatan dan wawancara terhadap pihak yang berkompeten terhadap data yang diperlukan.

3. Dokumentasi

Dokumentasi merupakan catatan peristiwa yang sudah berlalu (Sugiyono, 2008:422). Dalam penelitian ini metode dokumentasi digunkan untuk mengumpulkan data tentang alur proses rekondisi dan informasi.

\section{HASIL DAN PEMBAHASAN}

\section{A. Data Produksi}

Data produksi ini adalah data hasil produksi outsole di bagian hot press department technical yang di produksi PT. KMK Global Sports 2. Untuk kelengkapan di dalam melakukan analisa permasalahan dan melakukan perbaikan dan melakukan perhitungan maka data yang di ambil adalah data produksi outsole jenis AS Brown 475 pada tahun 2015. Untuk hasil data produksi outsole dapat dilihat pada Tabel 1.

Tabel 1 Data Produksi Outsole AS Brown 475

\begin{tabular}{|c|c|c|c|c|}
\hline No & $\begin{array}{l}\text { Bulan } \\
\text { (2015) }\end{array}$ & Produksi & Cacat & $\%$ \\
\hline 1 & Januari & 120120 & 1283 & $1,07 \%$ \\
\hline 2 & Februari & 110372 & 1616 & $1,46 \%$ \\
\hline 3 & Maret & 98720 & 1636 & $1,66 \%$ \\
\hline 4 & April & 84583 & 867 & $1,03 \%$ \\
\hline 5 & Mei & 67839 & 991 & $1,46 \%$ \\
\hline 6 & Juni & 88210 & 1224 & $1,39 \%$ \\
\hline 7 & Juli & 127990 & 2681 & $2,09 \%$ \\
\hline 8 & Agustus & 222319 & 3521 & $1,58 \%$ \\
\hline 9 & September & 180339 & 3458 & $1,92 \%$ \\
\hline 10 & Oktober & 110304 & 2066 & $1,87 \%$ \\
\hline 11 & November & 166049 & 2465 & $1,48 \%$ \\
\hline \multirow[t]{2}{*}{12} & Desember & 99107 & 1405 & $1,42 \%$ \\
\hline & Total & 1475952 & 23213 & $1,57 \%$ \\
\hline
\end{tabular}

(Sumber: PT. KMK Global Sports 2)

Berdasarkan Tabel 1 menunjukkan jumlah persentase produk cacat yang terjadi tahun 2015 sebanyak $1,57 \%$, sehingga total produk cacat yang terjadi pada tahun 2015 sebanyak 23213 Pcs.

\section{B. Jenis-jenis cacat dan Jumlah Cacat}

Berdasarkan ke enam jenis cacat outsole AS Brown 475 telah di ketahui masing-masing jumlah cacat menurut jenisnya. Adapun jenis dan jumlah cacat dapat di lihat pada Tabel 2.

Tabel 2 Jenis Cacat dan Jumlah Cacat Tahun 2015

\begin{tabular}{|c|l|c|c|}
\hline No & Jenis Cacat & Produksi & Jumlah Cacat \\
\hline 1 & $\begin{array}{l}\text { Kurang } \\
\text { Bahan }\end{array}$ & 1475952 & 11384 \\
\hline 2 & $\begin{array}{l}\text { Logo } \\
\text { Berbayang }\end{array}$ & 1475952 & 6250 \\
\hline 3 & Kotor Bahan & 1475952 & 2636 \\
\hline 4 & $\begin{array}{l}\text { Kurang } \\
\text { Angin }\end{array}$ & 1475952 & 1232 \\
\hline 5 & Pecah-pecah & 1475952 & 1011 \\
\hline 6 & Gosong & 1475952 & 700 \\
\hline
\end{tabular}

(Sumber: PT KMK Global Sports 2)

\section{Priorotas caact dengan Diagram Pareto}

Untuk kelengkapan di dalam melakukan analisa permasalahan dan melakukan tindakan perbaikan, maka data yang diambil adalah data dari bagian quality control, karena bagian quality control adalah bagian yang mengolah dan menganalisa untuk meminimalkan produk cacat.

Data tersebut kemudian dibuat diagram pareto. Berikut data produk cacat yang diolah kedalam diagram pareto. Data jenis cacat outsole AS 475 ada enam jenis, dari uraian diatas diketahui jenis cacat terendah dan terbesar. Cacat tertinggi outsole AS 475 yaitu cacat Kurang Bahan sebanyak 11384 Pcs atau 0,77\% dari total sebanyak 1475952 Pcs dan cacat terendah yaitu gosong sebanyak 700 Pcs atau $0,05 \%$ dari total produksi 1475952 Pcs.

Setiap cacat memiliki nilai persentase masalah, untuk menghitung nilai persentase masalah kurang bahan. Jadi untuk jenis cacat kurang bahan nilai persentase masalah adalah $49,04 \%$.

Untuk jenis cacat terendah adalah jenis cacat gosong. Untuk menghitung nilai persentase jenis cacat gosong. Jadi untuk jenis cacat gosong nilai persentase masalah adalah $3,02 \%$. Untuk mendapatkan nilai hasil pada jumlah cacat kumulatif adalah dengan cara memasukkan nilai cacat pertama dengan nilai cacat sesudahnya, sebagai contoh untuk cacat kumulatif logo berbayang. Untuk mendapatkan nilai persentase pada kumulatif. Diagram Pareto Produk Cacat Outsole AS 475 seperti Gambar 1. 


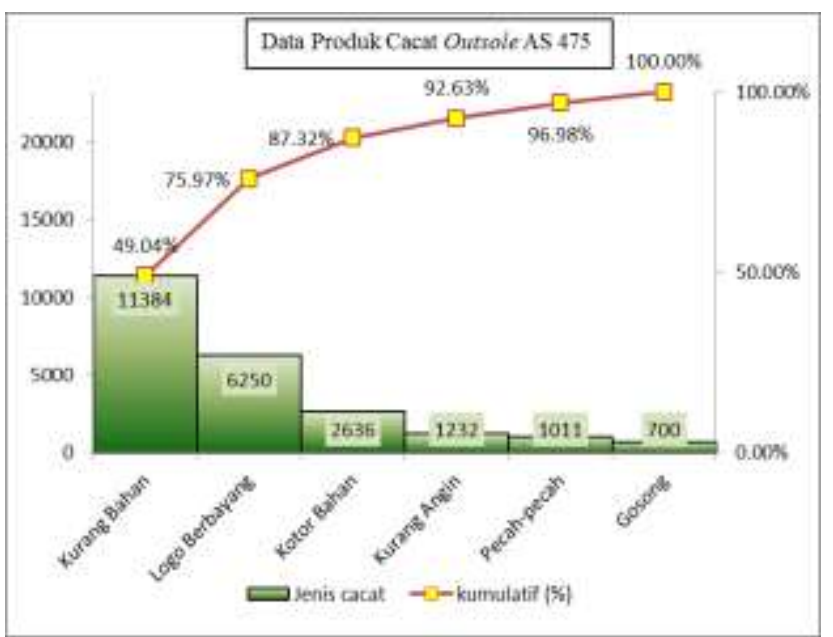

(Sumber: Diolah Sendiri Tahun 2016)

Gambar 1 Diagram Pareto Produk Cacat Outsole AS 475

Berdasarkan perhitungan kumulatif jenis-jenis cacat dapat disimpulkan dengan diagram pareto yaitu jenis cacat kurang bahan yang paling tinggi dengan persentase cacat adalah 49,04\% atau 11384 Pcs cacat, maka dari itu untuk memfokuskan analisa penulis akan menganalisa jenis cacat kurang bahan sebagai penilitian yang akan di lakukan.

\section{Penghitungan Statistik dengan diagram kendali $\mathbf{P}$.}

Perhitungan statistik dilakukan untuk mengetahui pengendalian kualitas yang ada pada perusahaan masih berada dalam batas kendali atau tidak, berdasarkan perhitungan kumulatif dengan diagram pareto penulis akan melakukan perhitungan diagram kendali $p$ dengan jenis cacat kurang bahan, hal ini karena jenis cacat kurang bahan adalah cacat yang paling dominan atau paling terbesar yang menyebabkan cacat outsole AS 475 yang bisa merugikan perusahaan.

Perhitungan nilai BKA, BKB dan P pada bulan selanjutnya sama dengan perhitungan nilai BKA, BKB, dan P pada bulan Januari.

Berdasarkan perhitungan hasil produksi dan cacat dengan pengamatan yang berbeda-beda maka perhitungan selanjutnya untuk membuat peta kendali p sebagai berikut:

1. Garis Sentral $=C L=P=0,00771$

2. $B K A=\frac{\sum B K A}{\sum \text { Bulan }}=\frac{0,10191}{12}=0,00849$

3. $B K B=\frac{\sum B K B}{\sum \text { Bulan }}=\frac{0,08320}{12}=0,00693$

\section{E. Failur Mode And Effect Analysis (FMEA)}

FMEA merupakan teknik evaluasi tingkat keandalan dari sebuah sistem untuk menentukan efek dari kegagalan dari sistem tersebut atau suatu metode apa saja yang termasuk dalam kecacatan/ kegagalan dalam desain, kondisi di luar batas spesifikasi yang ditetapkan atau perubahan-perubahan dalam produk yang menyebabkan terganggunya fungsi dari produk itu.

Adapun dari hasil analisa menggunakan metode FMEA untuk pemecahan masalah dengan hasil pengolahan yang dilakukan wawancara dan pengamatan langsung terhadap proses di line hot press outsole yang selalu menyumbangkan kerugian akibat nilai cacat yang cukup tinggi. Maka dari itu analisa FMEA bisa membantu menentukan prioritas kecacatan yang paling tinggi sebagai bahan pemecahan masalah.

Berdasarkan analisa menggunakan metode FMEA dapat dilihat dengan perhitungan sebagai berikut:

1. Proses Rheometer yang rusak

Nilai Severity: 3

Nilai Occurance: 2

Nilai Detection: 2

Jadi, Nilai RPN $=\mathrm{S} \times \mathrm{O} \times \mathrm{D}=3 \times 2 \times 2$ $=12$

2. Proses Middle Plate

Nilai Severity: 5

Nilai Occurance: 5

Nilai Detection: 2

Jadi, Nilai $\mathrm{RPN}=\mathrm{S} \times \mathrm{O} \times \mathrm{D}=5 \times 5 \times 2$ $=50$

3. Proses Cutting Dies

Nilai Severity: 7

Nilai Occurance: 3

Nilai Detection: 2

Jadi, Nilai $\mathrm{RPN}=\mathrm{S} \times \mathrm{O} \times \mathrm{D}=7 \times 3 \times 2$ $=42$

4. Proses Pemasangan Tambalan Kurang Pas

Nilai Severity: 9

Nilai Occurance: 6

Nilai Detection: 4

Jadi, Nilai $\mathrm{RPN}=\mathrm{S} \times \mathrm{O} \times \mathrm{D}=9 \times 6 \times 4$ $=216$

5. Alat Pengukur Pressure

Nilai Severity: 6

Nilai Occurance: 5

Nilai Detection: 3 
Jadi, Nilai $\mathrm{RPN}=\mathrm{S} \times \mathrm{O} \times \mathrm{D}=6 \times 5 \times 3$ $=90$

6. Proses Molding

Nilai Severity: 7

Nilai Occurance: 4

Nilai Detection: 4

Jadi, Nilai RPN $=\mathrm{S} \times \mathrm{O} \times \mathrm{D}=7 \times 4 \times 4=112$

Untuk proses selanjutnya menggunakan perhitungan pada proses yang sama seperti sebelumnya. Berdasarkan hasil perhitungan nilai RPN pada tabel menunjukan nilai tertinggi yaitu pada cacat kurang bahan dengan nilai 216 RPN dan nilai terendah yaitu cacat gosong dengan nilai 36 RPN. Berdasarkan hasil dari analisa FMEA maka penulis akan menganalisa faktor-faktor penyebab dari kegagalan nilai RPN tertinggi dengan menggunakan metode diagram sebabakibat.

\section{F. Usulan Tindakan Perbaikan}

Hasil analisa diagram sebab-akibat dapat dilihat faktor-faktor penyebab terjadinya cacat kurang bahan pada outsole AS 475, yang di lihat dari faktor mesin, manusia, material, metode dan lingkungan. Untuk tindakan selanjutnya adalah menanggulangi masalah tersebut sesuai dengan prioritas, sehingga langkah yang diambil dapat efektif dan tepat.

\section{G. Melaksanakan Perbaikan}

Berdasarkan penyebab-penyebab dari metode $5 \mathrm{~W}+1 \mathrm{H}$ penulis dapat memberikan usulan perbaikan dalam upaya meminimalkan produk cacat yang sering terjadi.

\section{H. Hasil Perbandingan Sebelum dan Sesudah Perbaikan.}

Berdasarkan hasil perbaikan yang telah dilakukan, penulis melakukan perbandingan dengan 8 bulan sesudah perbaikan dengan hasil rata-rata persentase cacat. Hasil Perbaikan sebelum dan perbaikan seperti Tabel 3.

Tabel 4.3 Hasil Perbandingan Sebelum Perbaikan

\begin{tabular}{|c|l|c|c|}
\hline No & Bulan (2015) & Produksi & Cacat \\
\hline $\mathbf{1}$ & Januari & 120120 & 1283 \\
\hline $\mathbf{2}$ & Februari & 110372 & 1616 \\
\hline $\mathbf{3}$ & Maret & 98720 & 1636 \\
\hline
\end{tabular}

\begin{tabular}{|c|l|c|c|}
\hline No & Bulan (2015) & Produksi & Cacat \\
\hline $\mathbf{4}$ & April & 84583 & 867 \\
\hline $\mathbf{5}$ & Mei & 67839 & 991 \\
\hline $\mathbf{6}$ & Juni & 88210 & 1224 \\
\hline $\mathbf{7}$ & Juli & 127990 & 2681 \\
\hline $\mathbf{8}$ & Agustus & 222319 & 3521 \\
\hline $\mathbf{9}$ & September & 180339 & 3458 \\
\hline $\mathbf{1 0}$ & Oktober & 110304 & 2066 \\
\hline $\mathbf{1 1}$ & November & 166049 & 2465 \\
\hline $\mathbf{1 2}$ & Desember & 99107 & 1405 \\
\hline Total & & $\mathbf{1 4 7 5 9 5 2}$ & $\mathbf{2 3 2 1 3}$ \\
\hline
\end{tabular}

(Sumber: PT. KMK Global Sports 2)

Berdasarkan data jumlah produksi dan jumlah cacat pada tahun 2015 di dapatkan ratarata persentase. Adapun perhitungan rata-rata persentasenya sebagai berikut:

Tahun 2015:

Persentase $=$

$$
\frac{\Sigma \text { Produksi }}{\Sigma \text { Cacat }} \times 100=\frac{1475952}{23213} \times 100=1,57 \%
$$

Tabel 4.4 Hasil Perbandingan Sesudah Perbaikan

\begin{tabular}{|c|l|c|c|}
\hline No & $\begin{array}{c}\text { Bulan } \\
(\mathbf{2 0 1 6})\end{array}$ & Produksi & Cacat \\
\hline $\mathbf{1}$ & Januari & 135400 & 986 \\
\hline $\mathbf{2}$ & Februari & 125600 & 1002 \\
\hline $\mathbf{3}$ & Maret & 245600 & 1100 \\
\hline $\mathbf{4}$ & April & 145000 & 867 \\
\hline $\mathbf{5}$ & Mei & 120100 & 1011 \\
\hline $\mathbf{6}$ & Juni & 165000 & 2741 \\
\hline $\mathbf{7}$ & Juli & 98100 & 672 \\
\hline $\mathbf{8}$ & Agustus & 263500 & 2030 \\
\hline Total & & $\mathbf{1 2 9 8 5 0 0}$ & $\mathbf{1 0 4 0 9}$ \\
\hline
\end{tabular}

(Sumber: PT. KMK Global Sports 2)

Berdasarkan data jumlah produksi dan jumlah cacat pada tahun 2016 di dapatkan ratarata persentase setelah melakukan perbaikan. Adapun perhitungan rata-rata persentasenya sebagai berikut:

$$
\begin{aligned}
& \text { Tahun 2016: } \quad \text { Persentase }= \\
& \frac{\sum \text { Produksi }}{\sum \text { Cacat }} \times 100=\frac{1298500}{10409} \times 100=0,80 \%
\end{aligned}
$$

Berdasarkan hasil perhitungan dari hasil perbandingan rata-rata persentase cacat di ketahui bahwa ada penurunan persentase cacat setelah dilakukan perbaikan pada setiap proses yang sebelumnya menyebabkan masalah yang cukup besar dengan jumlah cacat 23.213 pcs atau $1,57 \%$ dari hasil produksi pada tahun 2015 dan jumlah cacat pada 8 bulan setelah perbaikan mengalami penurunan yaitu 10.409 pcs atau $0,80 \%$ dari hasil produksi. Dalam hal ini perusahaan mendapatkan keuntungan dari penurunan biaya cacat yang dalam perhitungan 
jika harga satu pcs outsole cacat seharga $\$ 5$,(dengan kurs Rp 13.000,-/dollar) maka jumlah cacat pada tahun 2015 yaitu 23.213 pcs $\times$ Rp $65.000,-=\operatorname{Rp} 1.508 .845 .000,-$ tentu jumlah kerugian ini cukup besar. Dengan dilakukan perbaikan didapatkan hasil penurunan pada 8 bulan berikutnya yaitu 10.409 pcs $\times \mathrm{Rp}$ $65.000,-=\operatorname{Rp} 676.585 .000,-$ Hal ini dapat menguntungkan/bermanfaat untuk PT KMK Global Sports 2 dalam meminimalkan biaya cacat atau produk cacat yang sering terjadi.

\section{KESIMPULAN}

1. Analisis pengendalian kualitas pada departemen technical PT. KMK Global Sports 2 dengan menggunakan metode statistical processing control (SPC) bahwa pengendalian kualitas berada diluar batas kendali yang membuat kerugian pada perusahaan, adapun hasil perhitungan dengan menggunakan diagram peta kendali $\mathrm{p}$ dengan hasil ada tiga titik yang diluar batas kendali yaitu pada bulan april, juli dan desember. Oleh karena itu dilakukan perbaikan dengan mengetahui faktor-faktor penyebab potensi kegagalan dengan menggunakan metode failure mode and effect analysis (FMEA).

2. Dari hasil analisis dengan metode failure mode and effect analysis (FMEA) didapat proses-proses yang berpengaruh dalam potensi menyebabkan kegagalan/kecacatan seperti berikut:

a. Rheometer rusak yang mengakibatkan bahan yang tidak layak/tidak sesuai lolos terhadap pemeriksaan hal ini terjadi karena kurangnya perawatan.

b. Middle plate berkarat yang mengakibatkan outsole yang kotor saat pengepresan hal ini terjadi karena operator malas membersihkan dan lingkungan yang kotor.

c. Cutting dies kotor yang mengakibatkan bahan menjadi kotor dan bisa membuat cacat kotor pada outsole hal ini terjadi operator tidak membersihkan sisa potongan bahan yang berbeda jenisnya.

d. Proses pemasangan tambalan yang kurang pas yang mengakibatkan cacat kurang bahan karena operator ceroboh atau telah merasa terbiasa sehingga tidak mengikuti standar. e. Alat pengukur pressure rusak yang mengakibatkan kurang angin pada outsole karena tekanan udara yang tidak sesuai hal ini terjadi karena adanya kebocoran pada tabung udara.

f. Mold rusak yang mengakibatkan menipisnya lapisan mold karena pemakaian yang kasar dan tidak adanya pengecekan untuk dilakukan perawatan secara berkala.

g. Kualitas karet yang buruk yang mengakibatkan bahan karet menjadi tidak bisa mengembang saat pengepresan hal ini karena harga bahan yang dipakai tidak sesuai/murah.

h. Pengepresan yang terlalu cepat atau lambat yang mengakibatkan cacat pada logo karena operator malas menggunakan timer.

i. Tidak membersihkan mesin setelah dipakai yang mengakibatkan outsole menjadi kotor hal ini terjadi karena operator yang malas untuk membersihkan.

j. Menaruh outsole atau bahan tidak pada tempatnya yang mengakibatkan hasil outsole menjadi kotor hal ini terjadi karena operator tidak mengikuti standar penempatan outsole yang sudah disediakan.

Dari hasil analisis yang didapat dengan metode FMEA adalah pada proses pemasangan tambalan yang kurang pas mendapatkan nilai RPN yang tertinggi yaitu 216 RPN dengan perhitungan nilai severity $\mathrm{x}$ nilai occurance $\mathrm{x}$ nilai detection $=9 \mathrm{x} 6 \mathrm{x}$ $4=216$ RPN, hal ini tentu menjadi fokus prioritas untuk dilakukannya perbaikan.

3. Usulan tindakan perbaikan yang di ambil dari faktor-faktor penyebab kegagalan atau dari metode $5 \mathrm{~W}+1 \mathrm{H}$ dapat dilakukan beberapa usulan perbaikan yang penulis telah laksanakan pada penelitian ini yaitu sebagai berikut:

a. Pemasangan tambalan yang kurang pas dapat membuat perbaikan dengan cara membuat SOP pemasangan tambalan yang benar.

b. Peletakan bahan preform yang tidak benar, dapat melakukan perbaikan dengan cara mengajarkan langsung ke setiap operator tentang peletakan bahan yang benar.

c. Molding yang rusak, bisa melakukan perawatan secara berkala dan pencucian 
mold yang rutin untuk menghindari lapisan mold yang sudah menipis dan berkarat.

d. Tekanan udara dan panas mesin yang kurang, dapat melakukan pengawasan yang intens dengan mengatur tekanan udara dan suhu panas sesuai standar setelah itu kepala regu mengunci panel temperatur agar operator tidak memainkan temperatur udara dan suhu panas.

e. Kualitas bahan tidak baik/ bahan mati dapat melakukan perbaikan dengan cara penambahan waktu proses sulfuring yang sebelumnya 240 detik menjadi 300 detik agar proses penyatuan bahan rubber dan sulfur tercampur rata.

f. Ketebalan rubber yang tidak sesuai standar, pada dasarnya standar ketebalan yang dipakai itu adalah 6-7 mm, maka dari itu harus selalu melakukan pengecekan ketebalan dengan menggunakan alat ukur sebelum pada proses cutting preform.

g. Lingkungan yang tidak nyaman, lingkungan mesin hot press outsole yang cukup panas membuat operator merasa cepat lelah dan letih oleh karena itu usulan perbaikan yaitu memasang kipas angin pada area mesin sebagai pendingin agar operator tidak cepat merasa lelah dan letih.

\section{DAFTAR PUSTAKA}

Bayu Prestianto, Sugiono dan Susilo Toto R. 2003. Analisis Pengendalian Kualitas Pada PT Semarang Makmur.

Faiz Al Fakri. 2010. Analisis Pengendalian Kualitas Produk di PT. Masscom Graphy Dalam Upaya Mengendalikan Tingkat Kerusakan Produk Menggunakan Alat Bantu Statistik.

Gasperz, Vincent. 2005. Total Quality Management. PT. Gramedia Pustaka Utama. Jakarta.

Heizer, Jay and Barry Render. 2006. Operations Management
(Manajemen Operasi). Salemba Empat, Jakarta.

Hermawati dan Sunarto. 2007. Analisis Pengendalian Mutu produk PT Meiwa Indonesia Plant 2 Depok.

La Hatani. 2008. Manajemen Pengendalian Mutu Produksi Roti Melalui Pendekatan Statistical Quality Control (SQC).

M. Nur Nasution, M.Sc.,APU. 2015. Manajemen Mutu Terpadu, edisi ketiga. PT Ghalia Indonesia. Bogor.

Miftah. 2010. Fishbone Kaoru Ishikawa Sebagai Alat Pengendali Mutu. PT. Gramedia Pustaka, Jakarta

Nasution, M. N. 2005. Manajemen Mutu Terpadu. Edisi kedua. Ghalia Indonesia. Bogor.

Praptono, MA. 1986. Statistika Pengawasan Kualitas. Universitas Terbuka: Karunia, Jakarta.

Prawirosentono, Suyadi. 2007. Filosofi Baru Tentang Manajemen Mutu Terpadu Abad 21 "Kiat Membangun Bisnis Kompetitif". Bumi Aksara, Jakarta.

PT. KMK Global Sports 2. 2015 Database Departement Technical. TelesonicTangerang.

Schey. John A, 2009. Proses Manufaktur: Introduction To Manufacturing Processes, Edisi Ketiga, Andi Yogyakarta.

Sugiyono. 2015. Statistika Untuk Penelitian. Bandung : PT. Alfabeta.

Syarifudin Nasution dan Yandra Arkeman.2014. Identifikasi dan Evaluasi Resiko Menggunakan Fuzzy FMEA pada Rantai Pasok Argoindustri Udang di Himpunan Petani Udang Bogor. 